\title{
Production, Characterization and Antibacterial Activity of Mucor rouxii DSM-119 Chitosan
}

\author{
Shaaban A. Moussa ${ }^{1 *}$, Asmaa F. Farouk ${ }^{2}$, Klaus Opwis ${ }^{3}$ and Eckhard Schollmeyer ${ }^{3}$
}

${ }^{1}$ Genetic Engineering and Biotechnology Research Institute, Minufiya University, El-Sadat City, Egypt

${ }^{2}$ National Research Center, Textile Research Division, Dokki, Cairo, Egypt

${ }^{3}$ DTNW - Deutsches Textilforschungszentrum Nord-West e.V. Institut an der, Universität Duisburg - Essen, Krefeld, Germany

\begin{abstract}
The production, purification and antibacterial effect of chitosan from Mucor rouxii strain DSM-1191 were investigated throughout current study. Chitosan was characterized by infrared spectroscopy, titration and average molecular weight. Furthermore, the antibacterial activity of chitosan produced from Mucor rouxii DSM-1191, against Escherichia coli and Micrococcus leutus was determined. Scanning electron micrographs of treated Micrococcus leutus with fungal chitosan are also presented.
\end{abstract}

Keywords: M. rouxii; Chitosan polymer; Antibacterial activity

\section{Introduction}

Chitosan is a cationic biopolymer consisting of $\beta-(1 \rightarrow 4)$ linked $\mathrm{N}$-acetyl-D-glucosamine prepared from chitin by deacetylation with alkaline solution as shown in (Figure 1).

Over the last several years, chitinous polymers, especially chitosan, have received increased attention as one of the promising renewable polymeric materials for their extensive applications in the food industries (preservative, antimicrobial, coating, antioxidant) [1], cosmetology (hair additives, lotions, facial and body creams) [2,3], biotechnology (emulsifier, chelator, flocculent) [4], agriculture (fungicide, films, soil modifier, elicitor) $[5,6]$ in addition to its pharmacology and medicine uses (fabrics, fibers, artificial organs, drugs, membranes) [7,8].

Chitosan can also be found in the cell wall of certain groups of fungi, particularly zygomycetes. It is a straight chain natural hydrophilic polysaccharide having a three dimensional $\alpha$-helical configuration stabilized by intramolecular hydrogen bonding [9]. The production of chitin and chitosan from fungal sources has gained increased attention in recent years due to their potential advantages such as: independence of seasonal factor, wide scale production, simultaneous extraction, extraction process is simple and cheap which resulting in reduction in time and cost required for production [10] and also absence of proteins contamination, mainly proteins that could cause allergy reaction in individuals with shellfish allergies $[11,12]$. In addition, fungi can be grown easily on any simple medium or industrial by products therefore liberating the production of chitosan from the dependence on the seasonal shellfish industry [13].

The object of the current study is to produce chitosan using Mucor rouxii DSM- 1191as a source with an attempt to study physochemical properties of the prepared chitosan as a natural antibacterial agent against a gram-negative bacterium Escherichia coli and a gram-positive Micrococcus lutues strains.

\section{Experimental Section}

\section{Materials}

Fungal strain, M. rouxii DSM-1191 was grown in Yeast Peptone Glucose (YPG) Broth (YPG; Merck, Darmstadt, Germany) at $28^{\circ} \mathrm{C}$ for $72 \mathrm{~h}$ under shake incubation condition. Mycelial growth was harvested by centrifugation, washed twice with distilled water and then homogenized with $2 \% 1 \mathrm{~mol} . \mathrm{NaOH}$ at $90^{\circ} \mathrm{C}$ for $2 \mathrm{~h}$. The alkali insoluble fraction was separated, washed with distilled water and neutralized with $10 \%$ acetic acid.

\section{Characterization of produced chitosan}

The physico-chemical characteristics of produced chitosan, after different treatments in their preparation, were determined according to [14], whereas the molecular weights of prepared chitosan were determined by gel permeation chromatography (GPC) using refractive index detector (PN-1000, Postnova Analytics, Eresing, Germany). The method of [15] was applied for determination of the degree of deacetylation of produced chitosan.

\section{Microbial strains}

Escherichia coli DSMZ-498 and Micrococcus lutues ATCC-9341 were examined for their susceptibility and sensitivity toward the treatment with produced chitosan.

\section{Antimicrobial activity of chitosan}

Disk diffusion method: In our study, the antibacterial activity of the series of chitosan against gram negative bacterium E. coli DSMZ 498 and gram positive bacterium Micrococcus lutues ATCC 9341 were evaluated by zone of inhibition test.

Plate count agar: Different concentrations $0.1,0.2,0.4$ and $0.5 \%$ of $M$. rouxii chitosan, were separately added into $200 \mathrm{~mL}$ flasks containing $40 \mathrm{~mL}$, Yeast peptone glucose (YPG) broth. The sterilized flasks were cooled at $45^{\circ} \mathrm{C}$ then inoculated with $0.5 \mathrm{ml}$ from cells of each test microbe $\left(2 \times 10^{5} \mathrm{cell} / \mathrm{ml}\right)$. The inoculated flasks were incubated at $30^{\circ} \mathrm{C}$ for $24 \mathrm{~h}$. Surviving culture cells were counted by spreading on

*Corresponding author: Shaaban A. Moussa, Genetic Engineering and Biotechnology Research Institute, Minufiya University, El-Sadat City, Egypt, E-mail: shaus477@yahoo.de

Received October 27, 2011; Accepted December 13, 2011; Published December 15, 2011

Citation: Moussa SA, Farouk AF, Opwis K, Chollmeyer E (2011) Production, Characterization and Antibacterial Activity of Mucor rouxii DSM-119 Chitosan. J Textile Sci Engg 1:105. doi:10.4172/2165-8064.1000105

Copyright: (c) 2011 Moussa SA, et al. This is an open-access article distributed under the terms of the Creative Commons Attribution License, which permits unrestricted use, distribution, and reproduction in any medium, provided the original author and source are credited. 


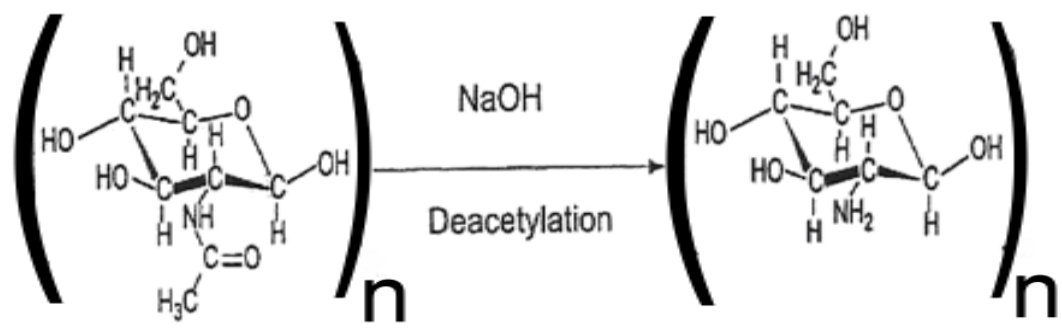

Chitin 2-acetamido-2-deoxy- $\beta$-D-glucose-( $\mathrm{N}$-acetylglucan)
Chitosan

2-acetamido-2-deoxy-3-D-glucose-( $\mathrm{N}$-acetylglucosamine)

Figure 1: The deacetylation process of chitin

nutrient agar (NA) plates. The inhibition ratios were calculated with the following formula:

$$
\text { Inhibition ratio }(\%)=(\mathrm{C}-\mathrm{E}) / \mathrm{C} \times 100
$$

Where $\mathrm{C}$ is the average number of the surviving cells of the control groups (zero chitosan concentration), $\mathrm{E}$ is the average number of the surviving cells of the chitosan concentrations.

Tetrazolium/formazan-test method: In the presence of bacteria, TTC is reduced to red formazan. The red formazan obtained indicates the activity and viability of the cells [16]. Therefore, the TTC- test method is considered a fast method for evaluating the antibacterial activity of chitosan. To do this test $100 \mu$ l of dissolved chitosan in $1 \%$ acetic acid was poured in $40 \mathrm{ml}$ nutrient broth medium containing 20 $\mu \mathrm{l}$ of $\left(10^{8} \mathrm{cfu} / \mathrm{ml}\right)$ challenge microorganisms E. coli and Micrococcus lutues) as an inoculums volume. Chitosan-free solution was used as a blank control., then all flasks were incubated with shaking at 37 ${ }^{\circ} \mathrm{C} / 200 \mathrm{rpm}$ for $3 \mathrm{~h}$, then $1 \mathrm{ml}$ from each flask containing the treated and the control was added to sterilized test tubes containing $100 \mu \mathrm{l}$ TTC $(0.5 \% \mathrm{w} / \mathrm{v})$. All tubes were incubated at $37^{\circ} \mathrm{C}$ for $20 \mathrm{~min}$. The resulted formazan was centrifuged at $4000 \mathrm{rpm}$ for $3 \mathrm{~min}$ followed by decantation of the supernatants. The pellets obtained were resuspended and centrifuged again in ethanol. The red formazan solution obtained at the end which indicated the activity and viability of the cells was measured by photometer at $480 \mathrm{~nm}$.

Micrograph capture:Toward the explanation of chitosan antimicrobial action, micrographs of treated Micrococcus lutues with fungal chitosan was captured using scanning electron microscope (Topcon-Microscope (ATB-55), Hitachi, Japan), after 1 and 5h from the treatment of Micrococcus leutus with chitosan, as well as control culture. Samples were prepared for scan electron microscope (SEM) as described by [3].

\section{Results and Discussion}

\section{Fungal chitosan production and analysis}

The growth of $M$. rouxii as well as chitosan production was dependent on the nutrients used and chemico-physical environment of the fermentation medium [17]. In this study the maximum value of the dry cell biomass of $M$. rouxii DSM-1191 strain under the fermentation condition with YBG culture medium at $28^{\circ} \mathrm{C}, 200 \mathrm{rpm}$ was $24.7 \mathrm{~g}$ (of dry mycelia per litre of medium) after $48 \mathrm{~h}$ of incubation the amount of the biomass decreased as the amount of nutrients decreased.
Extracted chitosan from the fungal mycelia after $48 \mathrm{~h}$ of fermentation reached $0.78 \mathrm{~g} / \mathrm{l}$ of dry mycelia weight. The decline of the extractable chitosan after $48 \mathrm{~h}$ of fermentation could be due to physiological changes in the fungal cell wall during the incubation period.

Results in (Table 1) show that growth curve and biomass yield of M. rouxii DSM-1191 increased rapidly up after $48 \mathrm{~h}$ of incubation; the maximum biomass yield during this time was $24.7 \mathrm{~g}$ of dry mycelia per litre after that the growth slowed down. In the case of chitosan, the yield increased with incubation time, the maximum yield of chitosan reached during this time was $0.78 \mathrm{~g} / \mathrm{l}$ dry mycelia weight after $48 \mathrm{~h}$ followed by decline when the culture was incubated after this point.

The main components of the mycelia are water, protein and alkali insoluble fraction containing chitin, chitosan and acidic polysaccharides [18]. During the incubation time the analysis of purified $M$. rouxii mycelia revealed that the protein contents gradually decreased from 6.35 to $5.85 \%$ on a dry weight basis of the mycelia (Table 2).

The degree of deacetylation has been found to influence the physical and chemical properties and biological activity of chitosan. The degree of deacetylation value for chitosan isolated from $M$. rouxii was $86 \%$, this result slightly different from the reported percentage degree of deacetylation of chitosan obtained from other fungal mycelia ranged from $65-95 \%[19,20]$.

\begin{tabular}{|c|c|c|}
\hline Growth time $(\mathrm{H})$ & Mycelial yield $(\mathrm{g} / \mathrm{l})$ & Chitosan yield $(\mathrm{g} / \mathrm{l})$ \\
\hline 12 & 4.8 & 0.22 \\
\hline 24 & 10.1 & 0.51 \\
\hline 48 & 12.9 & 0.78 \\
\hline 72 & 24.7 & 0.74 \\
\hline 84 & 16.3 & 0.61 \\
\hline
\end{tabular}

Table 1: Mycelial biomass and chitosan production from M. rouxii DSM-1191 grown in YPG medium at $28^{\circ} \mathrm{C}$

\begin{tabular}{|c|c|c|c|c|}
\hline \multirow{2}{*}{ Component } & \multicolumn{4}{|c|}{ Incubation Time (hours) } \\
\cline { 2 - 5 } & 12 & 24 & 48 & 72 \\
\hline Water (\%)* & 81.1 & 82.4 & 85.1 & 80.9 \\
\hline Proteins (\%) & 6.35 & 6.26 & 6.12 & 5.85 \\
\hline
\end{tabular}

Table 2. Changes in the mycelial component (water, protein content) during the incubation time of M. rouxii DSM-1191 
Citation: Moussa SA, Farouk AF, Opwis K, Chollmeyer E (2011) Production, Characterization and Antibacterial Activity of Mucor rouxii DSM-119 Chitosan. J Textile Sci Engg 1:105. doi:10.4172/2165-8064.1000105

Figure 2 showed the FTIR spectrum of chitosan from M. rouxii in compare with standard chitosan from Sigma. IR spectrum of chitosan was carried out using the $\mathrm{KBr}$ disc method. The main characteristic peaks of chitosan are at 3455 (-OH stretch), 2867 (C-H stretch), 1589 (N-H bend), 1154 (bridge O stretch), and $1094 \mathrm{~cm}^{-1}$ (C-O stretch). From the spectra there is no qualitative difference in peak locations between the standard chitosan and the fungal chitosan produced from $M$. rouxii strain especially in the amino characteristic peak at about $1589 \mathrm{~cm}^{-1}$.

The molecular weight of $M$. rouxii chitosan was $2.1 \times 10^{4}(\mathrm{Da})$ and this may be lower than that of crab chitosan.

\section{Surface topography of cotton fabrics}

The Surface of chitosan coated cotton fabrics were morphologically observed by scanning electron microscope (SEM) to investigate changes in the topography of the cotton fabrics Figure 3 shows the SEM micrograph of a sample of treated cotton, where the surface with no agglomerated particles are visible on the surface which indicates a homogeneous distribution of the chitosan in the coating layer and the absence of unwanted agglomeration during formation of the resulting coatings.

\section{Assays for antibacterial activity}

Antibacterial activity of $M$. rouxii DSM-1191 chitosan was
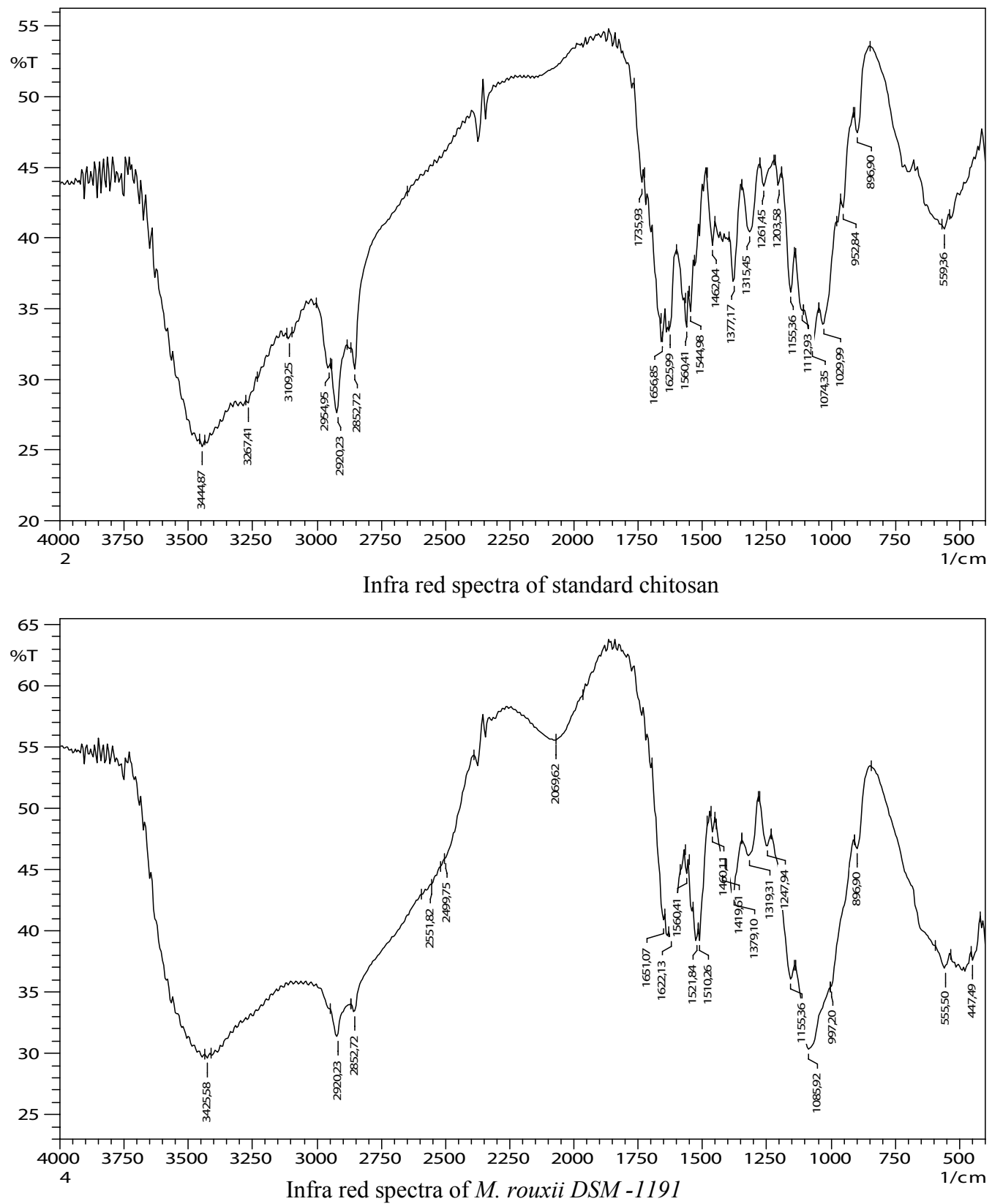

Figure 2: Infra red spectra of fungal chitosan from Mucor rouxii DSM-1191 (A) and standard chitosan (B). 
Citation: Moussa SA, Farouk AF, Opwis K, Chollmeyer E (2011) Production, Characterization and Antibacterial Activity of Mucor rouxii DSM-119 Chitosan. J Textile Sci Engg 1:105. doi:10.4172/2165-8064.1000105

examined against the E. coli DSMZ-498 and Micrococcus lutues ATCC9341 in the form of inhibition zones, evaluated by the disc diffusion assay, as shown in (Figure 4). The bactericidal activity against E. coli and $M$. lutues resulted in a clear zone of inhibition within and around the samples impregnated with different concentrations of chitosan. The antibacterial activity and inhibitory levels of chitosan have been shown to be significantly dependent on the degree of deacetylation (DD), and molecular weight (MW) [21].

Both photographs show the clear zone of inhibition around the discs impregnated with different concentrations of chitosan compared with untreated discs.

Using total count agar method, chitosan showed an excellent antimicrobial activity for both gram-negative bacterium E. coli and gram-positive bacterium Micrococcus luteus. Chitosan showed more effective suppression against Gram-positive bacterium Micrococcus luteus comparing to Gram-negative bacterium E. coli.

As shown in (Figure 5), treatment for $5 \mathrm{~h}$ with chitosan leads to $95 \%$ and $98 \%$ inhibition of $E$. coli and M. luteus growth respectively.

In the TTC test method the antibacterial activity of chitosan was estimated for the E. coli and Micrococcus luteus, This test serves as indicating system for the determination of the viability of microorganisms, since absorbance of formazane is directly proportional to the amount of living bacteria as shown in (Figure 6).

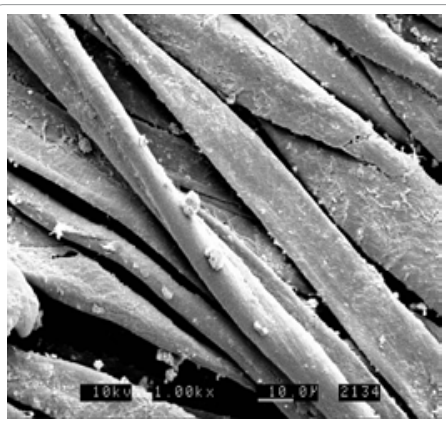

(A)

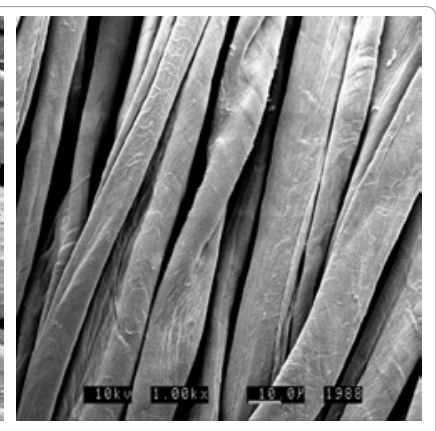

(B)
Figure 3: SEM micrographs of: (A) blank cotton fabric, $(B)$ cotton fabric treated with chitosan.

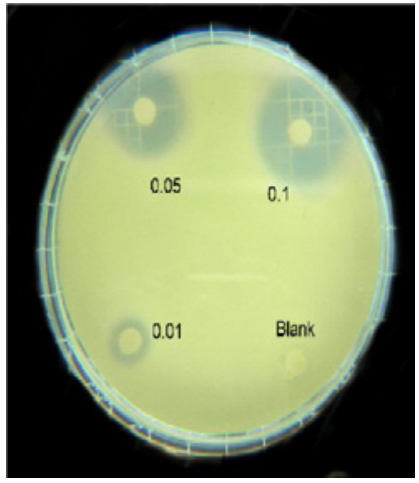

(A)

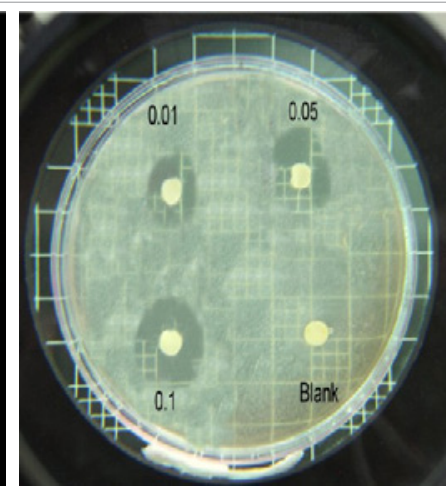

(B)
Figure 4: Disc diffusion test of different concentrations of chitosan (\%) for the growth inhibition of: Micrococcus luteus (A) and E.coli (B).

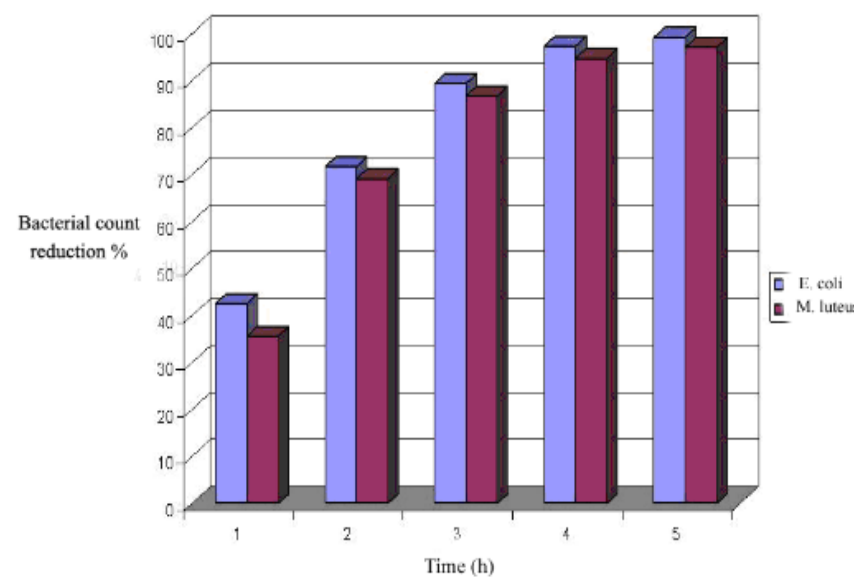

Figure 5: Antibacterial activity of $M$. rouxii chitosan against Gram-negative bacterium E.coli and Gram-positive bacterium Micrococcus luteus determined by plate count agar.

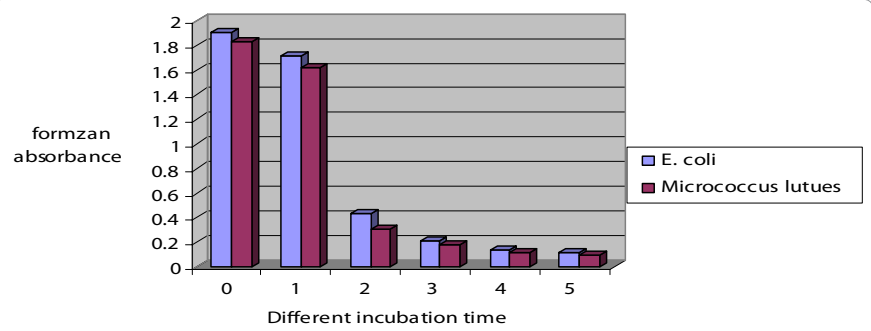

Figure 6: Absorbance of formazan for chitosan at different incubation time.

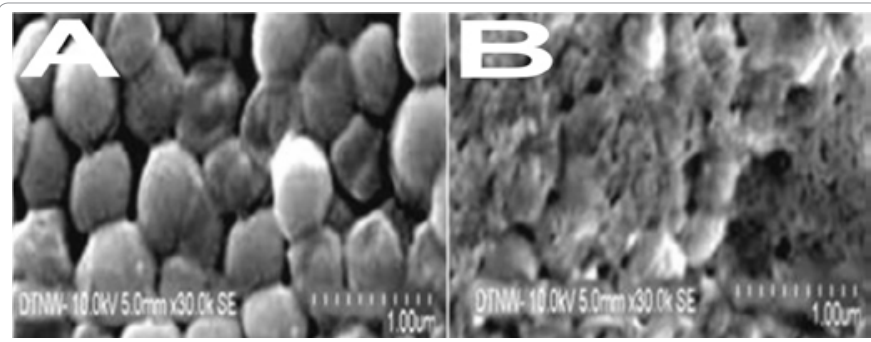

Figure 7: Scanning electron micrograph of Micrococcus lutues DSM-1191 treated with $1 \%$ of fungal chitosan. (A) Control (untreated) cells; (B) after $5 \mathrm{~h}$ from the treatment with chitosan.

\section{Scanning electron microscopic analysis}

Scanning electron micrographs of Micrococcus lutues treated with fungal chitosan, as well as control, are illustrated in (Figure 7). The micrographs pronounced that typical (untreated) cells had a normal smooth surface (Figure 7A), whereas after $6 \mathrm{~h}$ from the treatment of $M$. lutues with chitosan, cell wall was fully disrupted (Figure7B); cellular debris from cell lysis of $M$. lutues was observed as a mixture with cell wall residues.

The mode of action of chitosan biocides can be interpreted as follows: The bacterial cell surfaces are known to be negatively charged while chitosan is positively charged because of the presence of protonated amino groups, therefore the bacteria cell wall will be absorbed on the cationic surface of the chitosan membrane, which binds and disrupt the cytoplasmic membrane of the bacteria. The 
Citation: Moussa SA, Farouk AF, Opwis K, Chollmeyer E (2011) Production, Characterization and Antibacterial Activity of Mucor rouxii DSM-119 Chitosan. J Textile Sci Engg 1:105. doi:10.4172/2165-8064.1000105

Page 5 of 5

interaction between chitosan and microbial cells could be on the cell surface, which leads to increase permeability of cell wall and leakage of intracellular components, or inside the cell, which could inhibits DNA and RNA synthesis and directs cells into death [22; 23]. Rabea et al.[24] reported that the exact mechanisms for the antimicrobial effect of chitosan, chitin, and any other derivatives were unknown, although several mechanisms have been proposed. Several proposed mechanisms all involve some kind of damage or interaction with the cell membrane. One such proposed action is the positively charged chitosan interacting with the negative cell membrane which in turn alters its permeability, allowing leakage of intracellular material to the media $[25,26]$. This causes the release of cytoplasmic constituents, such as the DNA and the RNA, to take place continuously and eventually leading to death of the bacteria. Activity considerably varies with the type of chitosan, the target organism and the environment in which it is applied. Consequently, literature reports somewhat vary and are, occasionally, contradictory. But generally speaking, yeasts and moulds are the most sensitive group, followed by Gram-positive bacteria and finally Gram-negative bacteria [1]. Chitosans also could act as chelating agents that selectively can bind certain trace metals and thus inhibit microbial growth. Chitosan can activate several defense processes in the host issue, act as a water binding agent and inhibit various enzymes. Even binding of chitosan with DNA and inhibition of mRNA synthesis has been shown to occur through chitosan penetration towards the nuclei of the microorganisms and interfering with the synthesis of mRNA [24].

\section{Conclusion}

Chitosan could be considered as a biocidal agent against a wide range of target organisms. $M$. rouxii DSM-1191 was a good candidate for chitosan production by fermentation which seems to be economical. The mycelia of M. rouxii DSM-1191 may serve as a source of chitosan obtained with yields after $48 \mathrm{~h}$ of fermentation was $0.78 \mathrm{~g} / \mathrm{l}$. M. rouxii DSM-1191 chitosan showed stronger bactericidal effects for both gram-positive Micrococcus luteus and Gram-negative bacteria E. coli.

\section{References}

1. Skjak-Braek G, Anthonsen T, Sandford PA (1989) Chitin and chitosan: sources, chemistry, biochemistry, physical properties, and applications.

2. Lang G, Clausen T (1989) The use of chitosan in cosmetics. In: Skjak-Braek, G., Thorleif Anthosen, T., Standford, P. (Eds.), Chitin and Chitosan. Sources, Chemistry, Biochemistry. Physical Properties and Applications. Elsevier Applied Science, London and New York.

3. Tayel AA, Moussa S, Klaus O, Dierk K, Eckhard S, et al. (2010) Inhibition of Microbial Pathogens by Fungal Chitosan. International Journal of Biological Macromolecules 47: 10-14.

4. Sandford PA (1989) Chitosan: commercial uses and potential applications. in Chitin and Chitosan: Sources, Chemistry, Biochemistry, Physical Properties and Applications. (Ed), Skjak-Braek S, Anthonsen T and Sandford P. Elsevier Applied Science, New York.

5. Hoagland PD, Parris N (1996) Chitosan/Pectin laminated films. J Agric Food Chem 44: 1915-1919.

6. Jiang Y, Li Y (2001) Effect of chitosan coating on postharvest life and quality of longa fruit. Food Chem 73: 139-143.

7. Kulpinsky P, Nishimura S (1997) Preparation and characterization of new functionalized chitosan fibers. Adv Chitin Sci 2: 334-338.

8. Liu X F, Guan Y L, Yang Z, Li Z, Yao KD (2001) Antimicrobial action of chitosan and carboxymethylated chitosan. J Appl Polym Sci 79: 1324-1335.

9. Kas HS (1997) Chitosan: properties, preparations and application to microparticulate systems. J Microencapsulation 14: 689-711.
10. White SA, Farina PR, Fulton I (1979) Production and isolation of chitosan from Mucor rouxii. Appl Environ Microbial 38: 323-328.

11. Andrade VS, Neto BB, Souza W, Campos-Takaki GM (2000) A factorial designs analysis of chitin production by Cunninghamella elegans. Canadian Journal of Microbiology 46: 1042-1045.

12. Nadarajah K, Kader J, MazmiraMohd, PaulDC (2001) Production of chitosan by fungi. Pakistan Journal of Biological Sciences 4: 263- 265.

13. McGahren WJ, GA Perkinson, Growich JA, Leese RA, Ellestead GA (1984) Chitosan by fermentation. Process Biochem 19: 88-90.

14. AOAC (1990) Official Methods of Analysis. (13th edn), Association of official Analytical Chemists, Washington, DC, USA.

15. Donald HD, ER Hayes (1988) Determination of degree of acetylation of chitin and chitosan. Methods in Enzymol 161: 442-446.

16. Eloff JN (1998) A sensitive and quick microplate method to determine the minimal inhibitory concentration of plant extracts for bacteria. Planta Medica 64: 711-713.

17. Chatterjee S, Adhya M, Guha AK, Chatterjee BP (2005) Chitosan from Muco rouxii production and physico-chemical characterization. Process Biochem 40: 395-400.

18. Synowiecki J, Al-Khateeb NA (2003) Production, properties, and some new applications of chitin and its derivatives. Crit Rev Food Sci Nutr 43: 145-171.

19. Miyoshi H, Shimura K, Watanabe K, Kasuki O (1992) Characterization of some fungal chitosans. Bioscience Biotechnology and Biochemistry 56: 1901-1905.

20. Pochanavanich P, Suntornsuk W (2002) Fungal chitosan production and its characterization. Letters In Applied Microbiology 35: 17-21.

21. You-Jin Jeon, Pyo-Jam Park, Se-Kwon Kim (2001) Antimicrobial effect of chitooligsaccharides produced by bioreactor. Carbohydrate Polymers 44: 71 76.

22. Kato Y, Onishi H, Machida Y (2003) Application of chitin and chitosan derivatives in the pharmaceutical field. Curr Pharm Biotechnol 4: 303-309.

23. Gatenholm P, Ashida T, Hoffman AS (1997) Hybrid biomaterials prepared by ozone-induced polymerization. I. Ozonation of microporous polypropylene. J Polym Sci Part A: Polym Chem 35: 1461-1467.

24. Rabea El, Badawy ME, Stevens CV, Smagghe G, Steurbaut W (2003) Chitosan as Antimicrobial Agent: Applications and Mode of Action. Biomacromolecules $4: 1457-1465$.

25. Je JY, SK Kim (2006) Chitosan derivatives killed bacteria by disrupting the outer and inner membrane. J Agric Food Chem 54: 6629-6633.

26. Liu H, Y Du, Wang X, L Sun (2004) Chitosan kills bacteria through cell membrane damage. Int J Food Microbiol 95: 147-155.

27. Huang M, Khor E, Lim LY (2004) Uptake and cytotoxicity of chitosan molecules and nanoparticles: effects of molecular weight and degree of deacetylation. Pharm Res 21: 344-353. 